\title{
The contribution of water accounting to irrigation efficiency
}

\author{
P. Taylor ${ }^{1} \&$ E. Harris ${ }^{2}$ \\ ${ }^{1}$ Water Policy Services Pty Ltd, Sydney, Australia \\ ${ }^{2}$ Department of Natural Resources, New South Wales, Australia
}

\begin{abstract}
Water accounting can be a key to optimising the yield from water stored in dams. In particular, where large numbers of water users are supplied from a headwork, accurate accounting of each user's water during and between seasons and years can provide flexibility to water users and dam operators alike.

With diversification of irrigation, creativity in managing risk, both for dam operation and water use, becomes more important as a means to facilitate irrigators' varying and changing water requirements. In eastern Australia, parallel water accounting methods were developed by State governments, with slightly different features, related to the variety of climate, irrigation enterprise and levels of supply reliability suitable to the water users. The major rivers experience significant-to-extreme annual fluctuations in flow; consequently, water accounting methods developed to provide differential supply reliability from the same dam and foster economic productivity by providing irrigators with some choice in supply characteristics. Further, accounting has facilitated water saving between years and a degree of borrowing from future years, as well as reinforcing in the minds of irrigators the level of risk their choices reflect. This paper outlines the development of water accounting in Australia, the pre-requisites for its introduction, as well as its potential role and benefits for irrigation.
\end{abstract}

Keywords: water allocation and distribution, dam operation, irrigation efficiency, sustainability, river management, water accounting, capacity sharing.

\section{Introduction}

Irrigation schemes normally contain large numbers of water users, but the allocation and distribution of water is commonly managed uniformly and 
relatively inflexibly. Water accounting can have a role in permitting flexibility in several aspects of irrigation management, including (i) providing differential water volumes among irrigators (although infrastructure and layout may impose limitations - as in inter-connected paddy rice areas), (ii) allowing the continuation of water entitlements between seasons or years, (iii) providing differential long-term reliability, (iv) giving irrigators greater control over the timing, volume and long-term reliability of their supply.

Water accounting is defined as any method for assigning a volumetric account to each water user, which represents the water to which that user is entitled. The water account is maintained in a similar fashion to a monetary account, with inflows (deposits) and outflows and other reductions (withdrawals and fees). Knowing the amount of water in the account is useful to both the dam operator and the water user. Water accounting is closely related to water rights, whether or not the rights are legally formalised, but without legal security an effective water accounting system is more difficult to maintain because some of its value in providing certainty to the water user is counteracted.

Reliability of supply refers to the degree to which an individual's water entitlement can be satisfied in the long term. Water availability means the extent to which water is predicted to be available in a specified accounting period. In Australia, reliability is estimated by modelling, using data from the past 100 years or more and projecting equivalent climate and river flow into the following 100 years. Availability is determined by the conditions at the start of the accounting period and an assessment of possible changes during that period. Availability normally increases as conditions (for example inflows to the dam) improve.

Establishing water accounts for the water held behind a dam in storage, is a way to link the headwork element of an irrigation scheme with its downstream water distribution network. There is a tendency for the operation of large dams to be separated from the irrigation channel schemes they supply. However, water accounts directly linked to irrigators should help to ensure that the operation of both the dam and the distribution channels are meeting irrigators' requirements.

\section{Water rights and accounting in Australia}

\subsection{Origin and development of water rights}

Australia is the second driest continent after Antarctica. Hence, water for irrigation and other uses has relied on major infrastructure development starting early in the twentieth century. After the more economic water supply options had been taken up, focus shifted to improving the performance of existing schemes within sustainable limits. The need to better define available water and estimate long-term reliability provided the impetus for developing water user accounts. It also allowed the water requirements of the environment vis-à-vis water users to be better defined and it can accommodate changes to climatic conditions cater for improved understanding of ecological water requirements. 
The current legal basis for water allocation in Australia originated in the $18^{\text {th }}$ century application of the British common law by colonial governments, including the riparian doctrine which defines the rights of land owners to take water from streams. That legal regime failed in Australia because rivers were too extended and their flow too variable, so that land holders were taking it upon themselves to cut into upstream dams to obtain a 'reasonable' flow downstream. Furthermore, it was impossible to build a dam in the upper reaches of a river and guarantee the water would flow to a distant downstream diversion point without interference from riparians. Late in the $19^{\text {th }}$ century, royal commissions were held to investigate these problems, resulting in changes to the law (eg Victoria Irrigation Act, 1886, New South Wales, Water Rights Act, 1896) so that it was generally decided to vest water rights (the use, flow and control of water) in the Crown - a situation which continues to the present. Thereafter, the colonial (subsequently State) governments allocated water by the issue of licences and permits.

That change paved the way for a program of dam building from early in the $20^{\text {th }}$ century until the 1990s. When large dams were constructed, their water was assigned firstly to government built irrigation schemes and later to individuals outside the schemes. Burrinjuck Dam on the Murrumbidgee River, the most prolific major tributary of the Murray River, was completed in 1914, while the Murrumbidgee Irrigation Areas (MIA), which it supplied, were completed shortly afterwards, some $500 \mathrm{~km}$ downstream, through a $150 \mathrm{~km}$ diversion canal. When land in the MIA was apportioned to prospective irrigators, the volumes to be supplied were estimated by taking water orders and calculating the area to be irrigated, along with a formula for transit 'losses'. Private landholders along the river could apply for a licence for some of this water, which specified an area permitted to be irrigated. The area 'entitlement' or more accurately, a water order stating the area to be irrigated at the time, was then used by the dam operator to calculate how much water should be released.

Differences in irrigation enterprise and climate led to differences in water allocation schemes. Water use in northern Victoria was mainly supplied for the irrigation of improved pasture for dairying, which required a very reliable annual supply, as farmers would lose their milk quota if it was not fulfilled every year. Therefore, the Victorian government settled on a 'water right' at a level which could be supplied in all years except for the driest. This was possible because the flow in the Murray and Goulburn rivers, the main sources for northern Victoria, was more reliable than most tributaries of the Murray River to the north. If water remained available after the water right had been supplied, further 'sales water' would be announced for purchase. Over time, many irrigators came to rely annually on some sales water, as though it was part of their core entitlement.

By contrast, in New South Wales (NSW), rice growing made the major demand on water in the southern valleys. Although horticulture was important, it consumed less water. Rice, as an annual (non-staple) crop, could be planted in greater or lesser areas from year to year, and even if no water was available at all in a particular year, the enterprise could continue the following year. Many 
farmers in NSW therefore preferred a less conservative approach, because they could take greater advantage of good supply years and accept a greater risk of shortfall the following year - a 'use it now' policy.

This less conservative approach was given support after the review of Keepit Dam in 1969 (Munro et al. [1]), when its yield was found to be significantly less than originally estimated. The study led to the promotion of financial as well as hydrologic risk as the basis for public expenditure on water infrastructure and these principles were applied to dam design methodology (Munro [2]). Munro argued, after investigating Keepit Dam that "irrigation dams should not be regarded primarily as a drought- proofing project, but rather as a means of increasing production in non-drought years", and "the system of operating the dams should aim at irrigating the area which will provide optimum national net benefit". This approach formed the basis of water licensing policy in NSW for the next 20 years. This view was formed on the basis of calculations which seemed to demonstrate that taking as much advantage of 'normal' and 'good' years, by expanding production in those circumstances, would outweigh the benefits in the long term of operating more conservatively in order to provide irrigation drought-proofing. At the same time, some water uses, such as town water supply, still required a much more reliable supply from year to year.

\subsection{Change to volumetric allocation}

The Keepit Dam review and drought in the 1960's were the triggers for a shift to volumetric allocation of water in NSW. In order to give farmers an incentive to measure their water use and conserve water, as well as to ensure maximum efficiency of the dams, a state-wide volumetric conversion programme was initiated. The conversion formulae were intended to be based on history of water use, but ultimately political factors ensured that a uniform megalitre-per-hectare figure was applied for annual crops state-wide. Perennials such as fruit trees, vines and other 'permanent plantings' were given an annual volume entitlement along with 'high security' status, meaning higher priority. This laid the foundation for a two-class system of water entitlements for irrigation, applied in practice by dam operators retaining a volume of water in storage to guarantee a full supply for 'high security' water uses in the following year.

From this point, the availability of water at the beginning of each water year was defined as a percentage of the entitlement volume, calculated by estimating total water demand against water in storage and expected minimum inflow during the year. Thus, if $78 \%$ was announced, each irrigator on a 'normal' licence knew that $78 \%$ of the licensed entitlement volume was guaranteed for the year, although if good inflows occurred during the season, that percentage could be progressively revised upward. This situation led in turn to irrigators taking a greater interest in the nature of the risk of shortfall and planting accordingly.

\subsection{Development of water accounting}

The calculation of annual water availability requires information on future (next year's) demand, likely catchment runoff and river flow, dam storage behaviour and tributary flow contributions. However, to provide better estimates, 
predictive river models, initially based on long term monthly data and later upgraded to daily data, were developed to incorporate all the above (Simons [4]). This became very important in the 1990's when environmental water requirements were being identified and later included in statutory water sharing plans.

The dams are managed during the irrigation season using operational models which enable dam operator to decide how much water to release from time to time. Dam releases of water are adjusted daily or several times per day depending on downstream tributary inflows. These operational models are based on the predictive models but are continually re-calibrated using real time data. Any inflow during the current year is assigned to water entitlements to the point where $100 \%$ of current year's entitlement is available and the water set aside for the following year is also taken care of. Flow from tributaries entering the river downstream of the dam are also introduce into the accounts, as this uncontrolled flow needs to be made available to irrigators in place of water from the storage. During low-to-normal flows, dam releases are determined, using gauging stations located at the same travel time as the dam from water user off-take points.

The combination of a volumetric entitlement linked to water storage in the headworks, and the progressive updating by adding and subtracting from the entitlement, amounted to a de facto water accounting system. The next step was to allow some carrying over of entitlements to the following year. Thus, if less than $100 \%$ of that year's entitlement was taken by the irrigator (remembering that if availability was less than $100 \%$, the water user was not entitled to more), a certain proportion could be held over in storage and used the following year - in addition to the normal entitlement for that year. Farmers could benefit when a dry year was expected, along with a decision to use less water in the current year. However, some penalties applied to such carry-overs (to recognise evaporation losses and to prevent excessive storage of water) which could not be retained indefinitely without being lost. Borrowing from a future year was also permitted within limits.

These developments were providing irrigators with greater flexibility and were moving towards a system where water entitlements, being accounted separately, were becoming individualised.

Figure 1 shows the categories of water in the accounting scheme for New South Wales, and the manner in which carry-over and borrowing is accounted. The environment's water needs have legal priority in New South Wales. Therefore, all other water entitlements must be calculated after environmental water provisions have been established. The current arrangement uses a planning system in which water for the environment is excluded from water which may be abstracted for irrigation, by the application of environmental flow rules (such as minimum flow requirements) or through specific allocation for environmental purposes (e.g. 160,000 megalitres per year for the Macquarie Marshes, an internationally recognized wetland). Water may also be purchased from licensed water users by the government or a private person, to provide additional environmental benefits. 
Water for allocation and release in current year

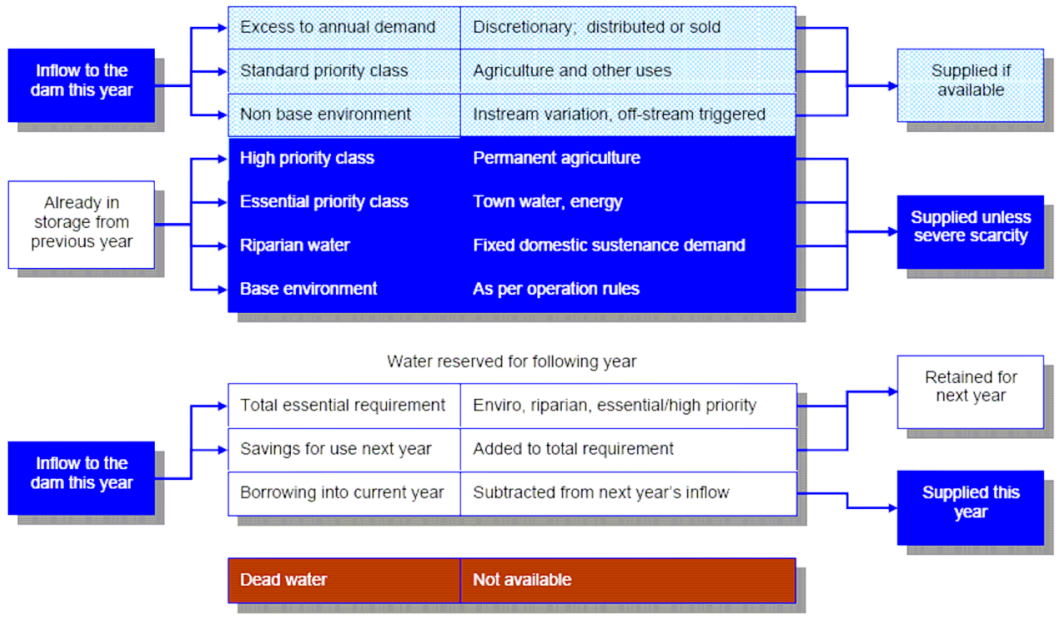

Figure 1: Example of categories of water in storage.

At the start of the water year, a determination of 'available water' is made and, on that basis, the dam operator releases water for the environment and the various classes of water user. In NSW, a riparian flow is also assigned for access by landholders who do not require a licence, but are allowed to take a restricted amount of water from rivers for domestic purposes. Water trading is also legally permitted, both temporary (meaning for one year or part of a year only) and permanent. When trades are made, the dam operator must adjust the relevant water accounts in the storage. Although the water accounting example shown in Figure 1 appears complex, in practice it is well understood by irrigators who are familiar with it as it applies to them.

An associated mechanism, known as capacity sharing, is also being used in Australia. Capacity sharing of water in storage is the method whereby the space in the storage is divided into shares, each of which is assigned to a different user, who also receive a proportion of inflow to the dam (Taylor et al. [3]). There are two examples of its use on a large scale, but with few users or 'shares'. Firstly, Lake Eucumbene, incorporated into the Snowy Hydro scheme, is divided into two 'developments' which earmark the water for discharge to the Murray River or the Tumut River. The water runs though a three-tier hydro-power facility in each case but to a different river. This was worked out to satisfy the water sharing interests of the States of New South Wales and Victoria, since the water was differently owned, depending on its destination. The second example, governed by the Murray-Darling Basin Agreement, involves the water sharing rights of the same two States. The storage space in the headwork dams, Hume and Dartmouth, is notionally divided equally into two halves in which inflow is stored for the two States. In the past, the State water shares were re-set to zero and the end of each year. As a result, NSW was taking more than $50 \%$ of the 
water because of its less conservative policy, and Victoria was therefore unhappy. The capacity sharing arrangement redresses the balance to a significant degree by allowing Victoria to hold up to $50 \%$ of storage space, after which further inflow, which would otherwise be allocated to Victoria, 'spills' into NSW's storage space and water account.

Capacity sharing has been promoted as the ultimate water allocation methodology for large numbers of water users, which would give water users complete control over their entitlements and allow them to act quite independently of other entitlement holders. In reality, capacity sharing must be tempered by general rules governing storage losses, and minimum and maximum storage volumes need to be applied in order to protect the economic efficiency of the dam and the value of all water entitlements. Further, changes over time in user demand pattern and reliability criteria cannot be completely cordoned off from the behaviour of the dam storage as whole. Capacity sharing for large numbers of water users was investigated by the governments of New South Wales and Victoria and rejected on the grounds of cost versus estimated benefit.

\section{Features of storage water accounting}

\subsection{Prerequisites}

Since governments are increasingly promoting improved irrigation performance and diversification, the benefits of dam storage water accounting should be considered. However, there are prerequisites, chiefly that water must be allocated by volume and its supply and use measured. Prerequisites for a water accounting system, as described earlier, are (i) a volumetric water entitlement system, preferably legally supported so that water entitlements are not subject to a dam or irrigation scheme operator's manipulation beyond operational and technical elements - i.e. entitlements cannot be administratively or arbitrarily reallocated or significantly altered in value by an agency except with due legal process, (ii) a sufficiently accurate measuring and recording system to update the account that defines the volume to which the user is entitled, (iii) an information system which provides current data to the dam operator and water user about water used, water available and predicted availability, (iv) a model that provides information on catchment and river system (all significant inflows to the point of water diversion) and predicts its behaviour under various operation and water demand scenarios. The options open to irrigators are also important.

\subsection{Benefits of water accounting}

Water accounting can assist in the provision of differential grades of reliability. Reliability (as an assurance of receiving the full volume of the entitlement in the long term) can be traded off against volume. This is occurring in the eastern States of Australia, under the general system, based on classes of priority. Thus, based on a conversion factor, a larger volume of water can be converted to a lesser volume with higher reliability. There are limits to such exchanges, 
because a dam supplying only entitlements with a high level of reliability would have to retain a large volume of water for the following year. This is the case for dams devoted entirely to urban and domestic water supply, where future certainty is very important, but the question of high degree of certainty versus volume is more relevant to irrigation. The natural tendency is to design for and promise a very reliable supply, but it may be the case that the long term economic benefit to irrigators would be greater in the long term if they took a greater risk. However, there are important social and economic factors to consider. Unless irrigators are able to survive a poor year or a series of poor years, they cannot so readily capitalise on the better years. Irrigators must also have the capacity to modify their agricultural practices in line with water availability. In many countries farmers do not have great flexibility.

Water accounting facilitates short-term water trading in Australia, where water is purchased for a single season or year, because both buyer and seller have a better understanding of the value of the remaining water entitlement. Water can be purchased part way through the year when a water user realises that more or less is needed to finish crop requirements.

Water accounts need adjustment in line with changes occurring to the whole of the storage and supply regime controlled by the dam and its operator. The factors affecting river management do not remain static in the long term, and therefore operation rules and guidelines need to be modified progressively.

Possible change factors for irrigation supplied from headworks include (i) location of irrigated area, (ii) extent of irrigated area - increase or decrease, (iii) type of crop and related demand pattern - seasonal timing, (iv) intensity of water application, (v) reliability requirement. Other changes to flow patterns may occur due to upstream diversions, change in catchment condition, urban development, climate change and change in the quality of water. In response, the dam operator needs to consider whether the value of water the entitlements of any group of water users or specific individuals will be significantly affected. An accounting system such as described helps the operator to identify the impacts of such changes and also to adjust for them.

The creation of water accounts call attention to the fact that each irrigator has a right to a specific volume of water in the headwork storage. Irrigators tend to take a more proprietary attitude to such accounts and consider them to be in the nature of a property. This may be intended by those who manage the schemes. In this view, the dam operator acts a storekeeper who manages accounts that belong to others, namely the water users. Likewise, an expectation may grow that the water should be more at the water user's disposal. This change of mindset could have implications for the relationship between irrigation scheme management and water users - promoting the idea that the scheme is a service which only operates for the benefits of the farmers, rather than the more paternalistic model as an institution which decides how and when to distribute water. This aspect should be recognised in any case where water accounting is being considered. Ideally the relationship between operator and irrigators is one of mutual negotiation and agreement on the nature of the services and the related operational rules and decisions. 


\subsection{Risk sharing and risk management}

An important outcome of water accounting is the fostering of a risk management approach by irrigators. This is demonstrably the case in Australia, where many irrigators, knowing that water availability fluctuates from year to year, are used to estimating the risk of shortfall and deciding how to proceed. Their understanding of risk results from experience in predicting the likelihood of water becoming available during the annual cycle, and where they have the ability to decide how much or what crop to plant, they learn from their decisions. Water accounting also causes water users to think volumetrically, provided they have some control over the diversion of water to the farm and an incentive to conserve water. Such thinking is conducive to the promotion of risk-sharing between irrigation scheme operators and irrigators, and the understanding of how to manage risk to advantage.

The recent Australian Intergovernmental Agreement on a National Water Initiative [5] identifies who should bear the risk of possible future reductions in water entitlement resulting from seasonal or long term changes in climate, increases in the knowledge of rivers' capacity to sustain water abstraction levels and increases in extraction and better understanding of the water needs of the environment. The National Water Initiative has specified a formula for cost sharing between water users and State and Federal governments.

\section{Conclusions}

Water accounting methods in south-eastern Australia evolved following the volumetric conversion of irrigation water entitlements, which drove the idea that the volume of water assigned to each water user should be clearly identified. This in turn enabled more flexible water management with a number of important characteristics, namely (i) widening of choices by the water user as to how much water to use in any season or year, (ii) adoption of some risk by water users, (iii) incentives for efficient water use, and (iv) facilitation of water trading. Water accounting also allows water users to obtain a more exact definition of the water to which they are entitled at any time.

Water accounting is most likely to provide benefits where (i) there is relatively frequent and significant water scarcity and failure to fulfil water demand, (ii) two or more types of water user with differential reliability requirements or demand patterns are supplied from the same headworks, or there is an opportunity to develop differential types of irrigation, (iii) irrigators have the ability to make individual choices about how much water to apply to land and what land to irrigate.

Finally, water accounting is a basic mechanism to achieve and maintain sustainable irrigation both from an economic and ecological perspective. It allows for orderly changes in demand and supply and reduces conflict between users and also enables environmental requirements to be identified and managed. 
364 Sustainable Irrigation Management, Technologies and Policies

\section{References}

[1] Munro C.H, Buddee, W F. and Brown, P B. "Water Licensing Policy". In An Economic Study of Keepit Dam, International Engineering Services Consortium. Australia, The Water Conservation and Irrigation Commission of NSW. Appendix N. 1969.

[2] Munro C.H, Australian Water Resources and their Development. Angus and Robertson Sydney, 1974.

[3] Taylor P, Harris E, Frazer S, Principles and practices of water allocation among water-use sectors, ESCAP Water Resource Series No 80 United Nations, 2000.

[4] Simons M, Podger G and Cook R IQQM - A Hydrologic Modelling Tool for Water Resource and Salinity Management, Environmental Software Vol 11, Nos 1-3 pp185-192, 1996.

[5] Council of Australian Governments, Intergovernmental Agreement on the National Water Agreement, 2004. 